\title{
Rapid prefractionation of complex protein lysates with centrifugal membrane adsorber units improves the resolving power of
} 2D-PAGE-based proteome analysis

\author{
Mary Kathryn Doud ${ }^{1}$, Michael W Schmidt ${ }^{1}$, David Hines ${ }^{2}$, \\ Claudia Naumann ${ }^{3}$, Andreas Kocourek ${ }^{3}$, Noushin Kashani-Poor ${ }^{3}$, \\ Robert Zeidler ${ }^{3}$ and Dieter A Wolf*1
}

\begin{abstract}
Address: ${ }^{1}$ Harvard NIEHS Center Proteomics Facility, Department of Genetics and Complex Diseases, Harvard School of Public Health, Boston, USA, ${ }^{2}$ Vivascience, Inc., Carlsbad, USA and ${ }^{3}$ Vivascience AG, Hannover, Germany

Email: Mary Kathryn Doud - mdoud@hsph.harvard.edu; Michael W Schmidt - mschmidt@hsph.harvard.edu; David Hines - David.Hines@vivascience.com; Claudia Naumann - Claudia.Naumann@vivascience.com; Andreas Kocourek - Andreas.Kocourek@vivascience.com; Noushin Kashani-Poor - Noushin.Kashani-Poor@vivascience.com; Robert Zeidler - Robert.Zeidler@vivascience.com; Dieter A Wolf* - dwolf@hsph.harvard.edu

* Corresponding author
\end{abstract}

This article is available from: http://www.biomedcentral.com/l47/-2/64/5/25

(c) 2004 Doud et al; licensee BioMed Central Ltd. This is an Open Access article: verbatim copying and redistribution of this article are permitted in all media for any purpose, provided this notice is preserved along with the article's original URL.

\begin{abstract}
Background: Two-dimensional gel electrophoresis (2D-PAGE) has proven over the years to be a reliable and efficient method for separation of hundreds of proteins based on charge and mass. Nevertheless, the complexity of even the simplest proteomes limits the resolving power of 2DPAGE. This limitation can be partially alleviated by sample prefractionation using a variety of techniques.

Results: Here, we have used Vivapure lon Exchange centrifugal adsorber units to rapidly prefractionate total fission yeast protein lysate based on protein charge. Three fractions were prepared by stepwise elution with increasing sodium chloride concentrations. Each of the fractions, as well as the total lysate, were analyzed by 2D-PAGE. This simple prefractionation procedure considerably increased the resolving power of 2D-PAGE. Whereas 308 spots could be detected by analysing total protein lysate, 910 spots were observed upon prefractionation. Thorough gel image analysis demonstrated that prefractionation visualizes an additional set of 458 unique fission yeast proteins not detected in whole cell lysate.

Conclusions: Prefractionation with Vivapure $\mathrm{Q}$ spin columns proved to be a simple, fast, reproducible, and cost-effective means of increasing the resolving power of 2D-PAGE using standard laboratory equipment.
\end{abstract}

\section{Background}

Despite some limitations, 2-dimensional gel electrophoresis (2D-PAGE) [1] coupled to mass spectrometric protein identification remains one of the most reliable and reproducible means of proteome analysis. Due to the wide dynamic range of individual proteins in cells, which presumably varies over five to six orders of magnitude [2], a key requirement for a comprehensive proteome analysis is to reduce sample complexity to a level that permits access to low abundance proteins. Whereas the resolving 
power of 2D-PAGE is remarkable, biochemical prefractionation will further enhance resolution enabling a deeper view into complex proteomes (reviewed in [3]).

Prefractionation can be achieved by a number of techniques such as differential protein extraction, purification of cell organelles or protein complexes, preparative isoelectric focusing (IEF), or chromatographic techniques [4]. Many of these procedures are time consuming, difficult to reproduce and scale up, result in sample loss, and often require expensive instrumentation such as liquid chromatography systems.

Here, we have tested Vivapure Ion Exchange Spin Columns employing a membrane adsorber technology as the chromatography matrix to fractionate proteins based on differences in charge. Unlike traditional chromatography resins, membrane adsorbers make use of convective transport to bring proteins to the ion exchange surface in microcentrifuge format. Hence, the binding, washing, and elution steps are performed rapidly in standard laboratory equipment. Moreover, the use of low binding materials together with centrifugal elution ensures highly efficient sample recovery.

While this method should have application to a broad range of cell types, we demonstrate here its utility for increasing the resolving power of 2D-PAGE-based proteome analysis of the fission yeast Schizosaccharomyces pombe.

\section{Results and discussion}

Total S. pombe cell lysate was prepared by bead lysis as described in the Methods section. An aliquot of this lysate was precipitated with trichloroacetic acid (TCA), followed by resuspension of the protein pellet in IEF buffer. $0.8 \mathrm{mg}$ of protein was separated by IEF on nonlinear $\mathrm{pH}$ 3-10 immobilized gradient strips and second dimension SDS gel electrophoresis. Gels were stained with SYPRO Ruby, and stained protein spots were detected by fluorescence scanning. Image analysis revealed that this technique detected 308 unique protein spots in total $S$. pombe cell lysate (Fig. 1A). In contrast, the theoretical proteome of this organism comprises 4395 proteins within a pI range between 3.0 and 10.0 (Fig. 1B).
(A)

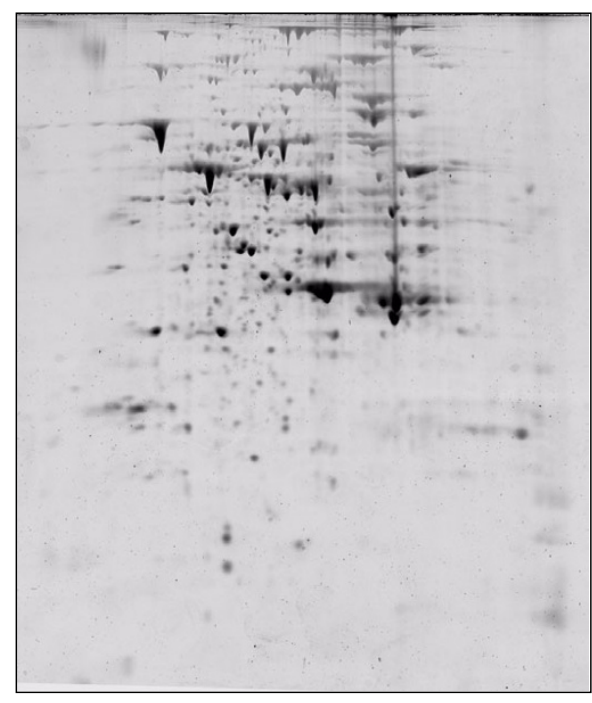

308 spots
(B)

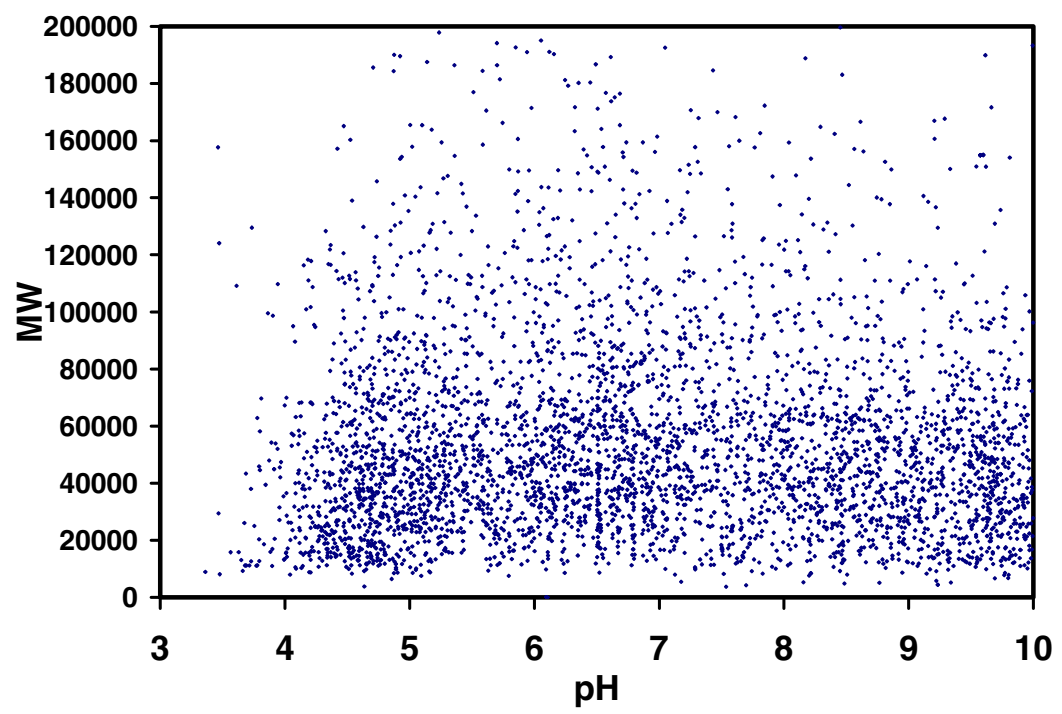

4395 proteins

\section{Figure I}

Practical and theoretical 2D-PAGE analysis of total S. pombe cell lysate. (A) $0.8 \mathrm{mg}$ total S. pombe protein lysate was separated by 2D-PAGE as described in Methods. The gel was stained with SYPRO Ruby and analyzed with the Phoretix 2D imaging software. (B) All proteins in the Sanger Centre S. pombe genome database with pl values between 3.0 and I0.0 possessing a molecular weight below $200 \mathrm{kDa}$ were blotted in the diagram to indicate a virtual whole cell 2D-PAGE. 
To increase our penetration of the fission yeast proteome, we sought a simple and reproducible method to prefractionate cell lysate using Vivapure anion exchange spin columns. $4 \mathrm{mg}$ total cell protein was applied to the column in a volume of $400 \mathrm{ul}$ and eluted with increasing concentrations of sodium chloride in increments of $50 \mathrm{mM}$. Fig. 2 summarizes the binding and elution characteristics of the spin column. Binding efficiency to the membrane adsorber was $~ 55 \%$ of the total protein loaded, and 94\% of bound protein was recovered at the end of the step gradient at $1 \mathrm{M} \mathrm{NaCl}$ (Fig. 2A,2B). 38\% of the loaded protein eluted between $50 \mathrm{mM}$ and $500 \mathrm{mM} \mathrm{NaCl}$. Gel analysis of individual fraction revealed a different pattern of proteins in the fractions eluted with $225 \mathrm{mM}, 300 \mathrm{mM}$, and 500 $\mathrm{mM} \mathrm{NaCl}$ (Fig. 2C).

Based on these findings, we devised the 2D-PAGE compatible prefractionation scheme outlined in Fig. 3A. In brief, total cell lysate was precleared by ultracentrifugation, loaded on a Vivapure anion exchange column, followed by separation into three fractions with step gradients of $225 \mathrm{mM}, 300 \mathrm{mM}$, and $500 \mathrm{mM} \mathrm{NaCl}$. Samples were then precipitated with TCA/acetone, resuspended in IEF buffer, and analyzed by 2D-PAGE.

Fig. 3B shows the elution profiles of two independent samples. The nearly complete overlap of the two curves indicated that the prefractionation and step elution was highly reproducible. In addition, the three fractions contained a similar amount of protein $(\sim 0.5 \mathrm{mg})$. The 2DPAGE analysis showed that prefractionation enriched for many proteins that were not visible in unfractionated lysate (Fig. 3C). Whereas 308 spots were visible in the total cell lysate, 307, 302, and 283 spots were observed in fractions 1, 2, and 3, respectively (Fig. 3C and Table 1). In addition, as expected for successful fractionation by charge, there was a successive enrichment of more acidic proteins as the $\mathrm{NaCl}$ concentration of the elution buffer increased (Fig. 3C). Overall, the spin column prefractionation led to a similar deconvolution of sample complexity as we had previously observed with anion exchange chromatography on an automated FPLC system [4].

More detailed comparative image analysis of corresponding gel areas revealed many spots that were only detectable upon prefractionation. As an example, a zoom-in image of a section of the fraction 3 gel (elution with 500 $\mathrm{mM} \mathrm{NaCl}$ ) showed an array of acidic proteins undetectable in total lysate (Fig. 4A). Further quantitation showed that 156 proteins were uniquely enriched in fraction 1 , 175 in fraction 2, and 127 in fraction 3, but not present in total cell lysate (Fig. 4B). Alltogether, 766 unique spots can be visualized in the three fractions.

\section{Conclusions}

Prefractionation with centrifugal membrane adsorber units was found to be a simple and reliable method to increase the resolving power of 2D-PAGE. Prefractionation led to a threefold increase in the number of features descernible by 2D-PAGE. Approximately 50\% of these features are uniquely represented in the fractions, but not in total protein lysate.

\section{Methods \\ Preparation of total cell lysate}

A liquid culture of $50 \mathrm{ml}$ fission yeast cells (927 h-leu1-32 ura4-d18) was grown at $30^{\circ} \mathrm{C}$ to an $\mathrm{OD}_{595}$ of 1.5 . Cells were harvested by centrifugation, frozen at $-80^{\circ} \mathrm{C}$, and resuspended in $500 \mathrm{ul}$ lysis buffer $(100 \mathrm{mM}$ sodium bicarbonate $\mathrm{pH} 8.8,0.5 \%$ Triton X100, and protease inhibitors (1 mM PMSF, $10 \mathrm{ug} / \mathrm{ml}$ leupeptin, $10 \mathrm{ug} / \mathrm{ml}$ pepstatin, 15 $\mathrm{ug} / \mathrm{ml}$ aprotinin)). Cells were disrupted by bead lysis in a microfuge tube containing $0.5 \mathrm{ml}$ Zirconia beads $(0.5$ $\mathrm{mm}$, Biospec Products. Inc.) and the cell debris was removed by centrifugation for 15 minutes at $4^{\circ} \mathrm{C}$. The protein concentration was determined with the BioRad DC Protein Assay using BSA as a standard. $1 \mathrm{ml}$ protein lysate $(\sim 10 \mathrm{mg} / \mathrm{ml})$ was incubated with $100 \mathrm{ug} / \mathrm{ml}$ RNAseA and DNAseI for 15 minutes on ice and cleared by ultracentrifugation at $395,000 \times \mathrm{g}$ for 30 minutes at $20^{\circ} \mathrm{C}$.

\section{Prefractionation on membrane adsorber units}

A Vivapure Q Mini spin column was equilibrated with $100 \mathrm{mM}$ sodium bicarbonate buffer, $\mathrm{pH} 8.8$ by loading $400 \mu \mathrm{l}$ onto the column and spinning at $2000 \times \mathrm{g}$ for 5 minutes. 400 ul lysate ( $=4 \mathrm{mg}$ protein) was loaded onto the equilibrated spin column and spun at $2000 \times \mathrm{g}$ for 5 minutes. After binding, the column was washed twice with 400 ul $100 \mathrm{mM}$ sodium bicarbonate, $\mathrm{pH}$ 8.8. Fraction 1 was eluted by loading 400 ul $100 \mathrm{mM}$ sodium bicarbonate, $\mathrm{pH} 8.8$ containing $225 \mathrm{mM} \mathrm{NaCl}$ onto the column and spinning at $2000 \times \mathrm{g}$ for 5 minutes. Subsequent elutions were performed with 400 ul $100 \mathrm{mM}$ sodium bicarbonate buffer, $\mathrm{pH} 8.8,300 \mathrm{mM}$ (fraction 2) or $500 \mathrm{mM} \mathrm{NaCl}$ (fraction 3), respectively.

\section{D-PAGE analysis}

Fractions, as well as the total lysate, were quantified and then precipitated by adding 3 volumes of chilled $\left(-20^{\circ} \mathrm{C}\right)$ $13.3 \%$ TCA / $0.093 \%$ 2-mercaptoethanol in acetone, followed by incubation overnight at $-20^{\circ} \mathrm{C}$. Samples were centrifuged at $5000 \times \mathrm{g}$ at $-20^{\circ} \mathrm{C}$ and pellets were resuspended in chilled $\left(-20^{\circ} \mathrm{C}\right)$ acetone, containing $0.07 \% 2$ mercaptoethanol. Samples were spun again at $5000 \times \mathrm{g}$ at $-20^{\circ} \mathrm{C}$. All acetone was removed and the pellets left to dry at $30^{\circ} \mathrm{C}$. The pellets were then redissolved at $30^{\circ} \mathrm{C}$ in CHAPS buffer ( $7 \mathrm{M}$ urea, $2 \mathrm{M}$ thiourea, 2\% CHAPS, 2\% ampholytes 3-10, 65 mM DTT, 0.1\% bromophenol blue) 
(A)

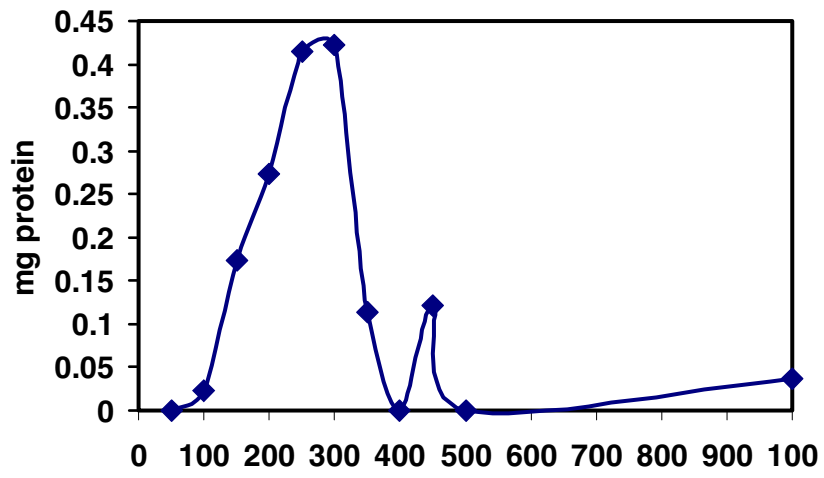

$\mathrm{NaCl}$ concentration (mM)

\begin{tabular}{lccc} 
(B) & mg & $\begin{array}{c}\text { \% of total } \\
\text { protein loaded }\end{array}$ & $\begin{array}{c}\text { \% of bound } \\
\text { protein }\end{array}$ \\
\hline \hline Load & 4.08 & 100.00 & \\
Flowthrough & 1.78 & 43.63 & \\
Bound before wash & 2.3 & 56.37 & \\
Wash & 0.62 & 15.20 & \\
Bound after wash & 1.69 & 41.42 & 100.00 \\
Eluted & 1.58 & 38.73 & 93.49
\end{tabular}

(C)

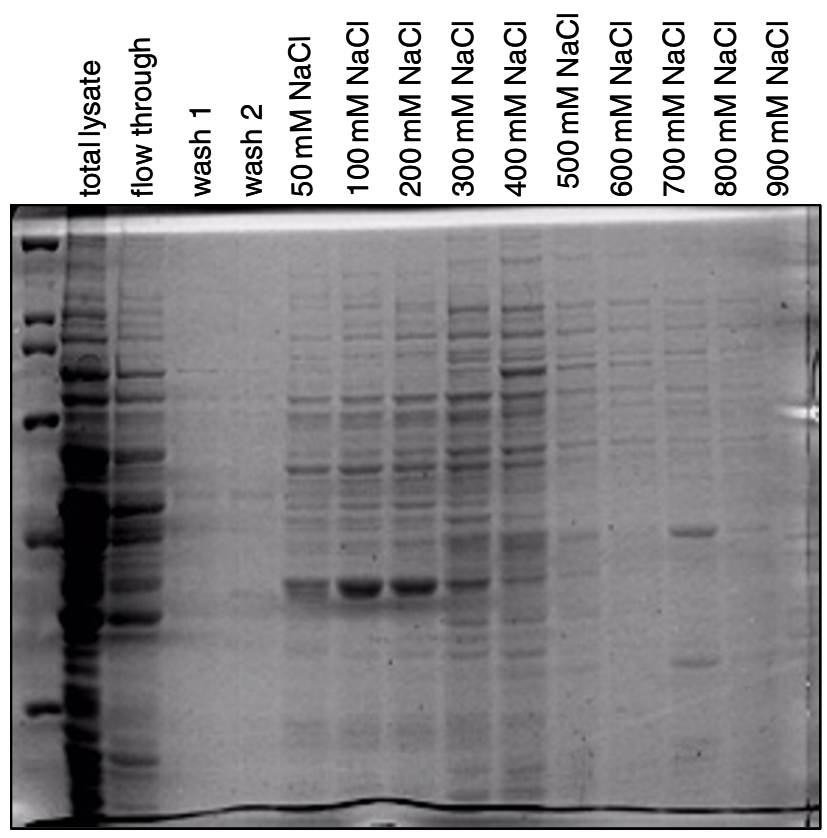

Figure 2

Sample prefractionation with Vivapure $\mathbf{Q}$ Mini spin columns (A) $4 \mathrm{mg}$ total fission yeast protein was loaded onto a Vivapure $\mathrm{Q}$ mini spin column, washed, and eluted with a $\mathrm{NaCl}$ step gradient from $50 \mathrm{mM}$ to I M. The elution profile is shown. (B) Summary of the binding and elution characteristics of Vivapure Q Mini columns. (C) Analysis of fractions by ID PAGE. The flowthrough as well as low and high salt fractions showed different protein patterns. 
(A)

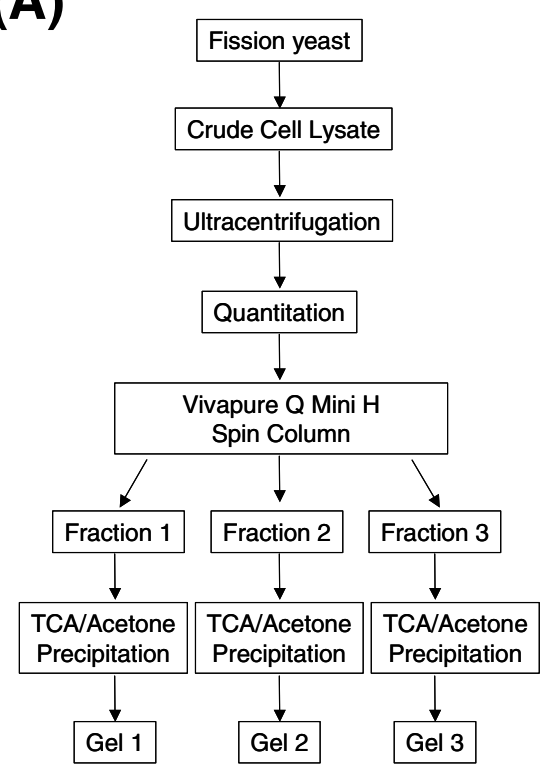

(B)

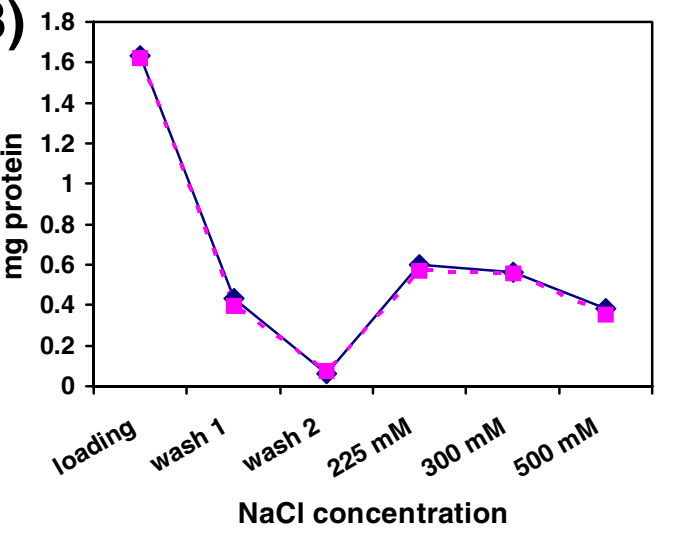

(C)

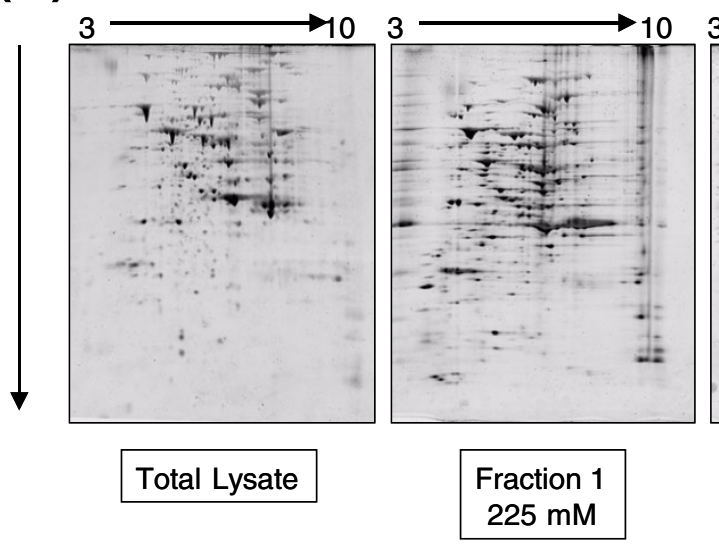

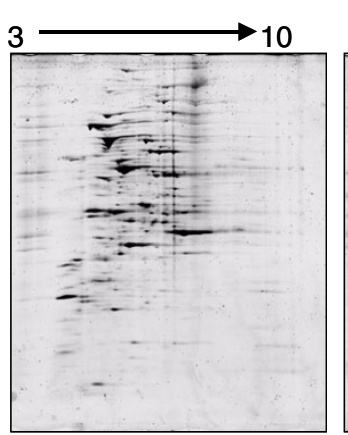

Fraction 2 $300 \mathrm{mM}$

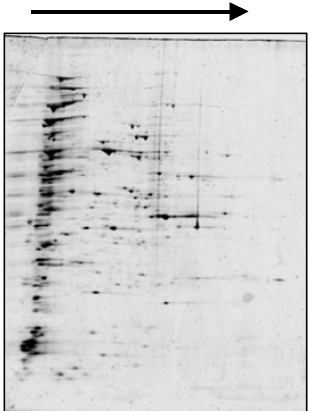

Fraction 3

\section{Figure 3}

2D-PAGE analysis of prefractionated $S$. pombe cell lysate (A) Workflow for fractionation using Vivapure Q spin columns by applying increasing $\mathrm{NaCl}$ concentrations for elution. See Methods for details. (B) Reproducibility of the prefractionation. Two independently prepared whole cell lysates were prefractionated on Vivapure Q Mini columns and eluted into three fractions with the indicated concentrations of $\mathrm{NaCl}$. The protein contents of the eluates are plotted. (C) 2D-PAGE of the three fractions compared to whole cell lysate. 


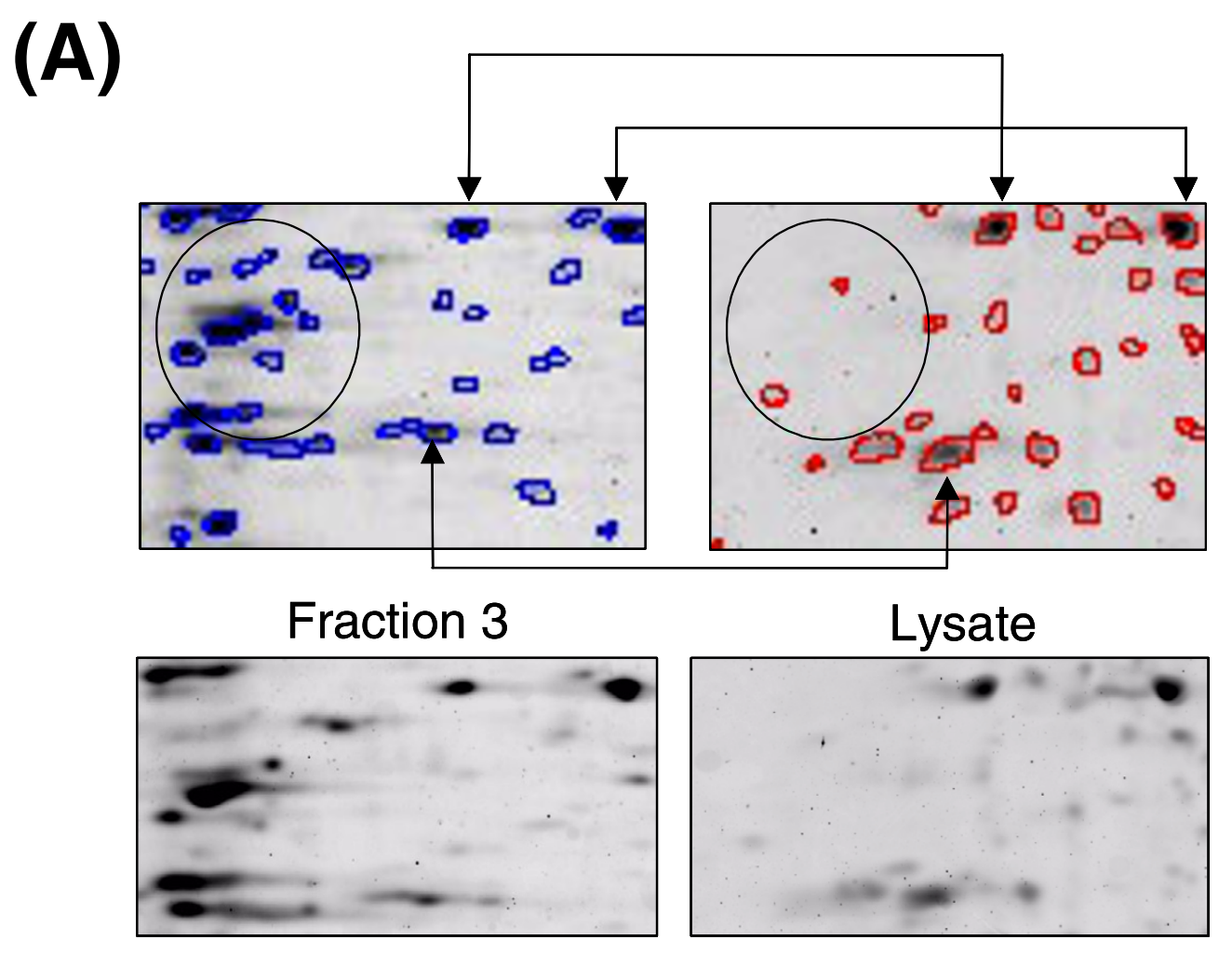

(B)

Number of Unique Spots Spots

\begin{tabular}{lll}
\hline \hline Total Lysate & 308 & 308 \\
& & \\
Fraction 1 & 307 & 156 \\
Fraction 2 & 302 & 175 \\
Fraction 3 & 283 & 127 \\
Total Number of & 910 & 458 \\
Spots in Fractions & &
\end{tabular}

\section{Total Number of Unique Spots}

766

\section{Figure 4}

Detailed analysis of 2D-PAGE results (A) Corresponding sections of the total lysate and fraction 3 gels are shown and spots only detected upon prefractionation are indicated. (B) Summary of the quantitation of the 2D-PAGE results. Image analysis was performed to identify protein spots that are only detected in a single fraction, but not in the total cell lysate. 
to a concentration of $2.5 \mathrm{mg} / \mathrm{ml} .400 \mathrm{ul}(1 \mathrm{mg})$ of this was loaded onto an $18 \mathrm{~cm}$ immobilized pH 3-10 nonlinear gradient strip (Amersham) and passively rehydrated for 16 hours. The strips were then focused to $100,000 \mathrm{Vh}$ (Genomic Solutions Investigator), equilibrated in $10 \mathrm{ml}$ equilibration buffer I ( $6 \mathrm{M}$ urea, $375 \mathrm{mM}$ Tris/ $\mathrm{HCl} \mathrm{pH} 7.4$, 2\% SDS, 2\% glycerol, 2\% DTT), followed by $10 \mathrm{ml}$ equilibration buffer II (6 M urea, $375 \mathrm{mM}$ Tris/HCl $\mathrm{pH} 7.4$, $2 \%$ SDS, $2 \%$ glycerol, $2 \%$ iodoacetamide), and applied to an $8-18 \%$ gradient Duracryl SDS PAGE gel (Genomic Solutions). The gels were stained with SYPRO Ruby and imaged on a BioRad Molecular Imager FX Pro Plus (532 nm excitation, $555 \mathrm{~nm}$ emission filter, $1064 \mathrm{~nm}$ excitation filter).

\section{Image analysis}

The images were analyzed using Phoretix 2D software from Nonlinear Dynamics. Spots were detected using automatic spot detection and the background was subtracted using the mode of non-spot method. The images were also subjected to spot filtering in order to remove spots occurring as a result of residual dye crystals. The three fractions were matched against the total lysate by placing thirty seed matches from which automatic matches were then made. The three fractions were also matched against one another by the same method to determine the number of unique spots in each fraction.

\section{List of abbreviations}

2D-PAGE; two-dimensional polyacrylamide gel electrophoresis

IEF; isoelectric focusing

SDS; sodium dodecyl sulfate

TCA; trichloroacetic acid

\section{Competing interests}

MKD received $\$ 500$ from Vivascience AG toward travel costs to the 2003 HUPO meeting in Montreal. No other competing interests.

\section{Authors' contributions}

MKD performed all the experiments shown in Fig. 1A,2, and 3. MWS contributed the data shown in Fig. 1B. CN, $\mathrm{AK}$, and NKP contributed to the development and optimization of the Vivapure spin column protocols. DAW, RZ, and $\mathrm{DH}$ conceived of the study, and participated in its design and coordination. All authors read and approved the final manuscript.

\section{Acknowledgements}

The authors thank Drs. Reif, Nussbaumer, and Demmer (Sartorius AG, Göttingen, Germany) for their support and assistance regarding Vivapure
Ion Exchange membrane adsorbers. This work was funded by the NIEHS Center grant ES00002 and by NIH grant ROI-GM9780 to DAW.

\section{References}

I. O'Farrell PH: High resolution two-dimensional electrophoresis of proteins. J Biol Chem 1975, 250:4007-402I.

2. Ghaemmaghami S, Huh WK, Bower K, Howson RW, Belle A, Dephoure N, O'Shea EK, Weissman JS: Global analysis of protein expression in yeast. Nature 2003, 425:737-74I.

3. Righetti PG, Castagna A, Herbert B, Reymond F, Rossier JS: Prefractionation techniques in proteome analysis. Proteomics 2003, 3:1397-I407.

4. Schmidt M, Jain A, Wolf DA: Multidimensional proteomic analysis of proteolytic pathways involved in cell cycle control. Cell Cycle Checkpoint Control Protocols Volume 24I. Edited by: Lieberman H B. Totowa, NJ, Humana Press; 2003:235-245.

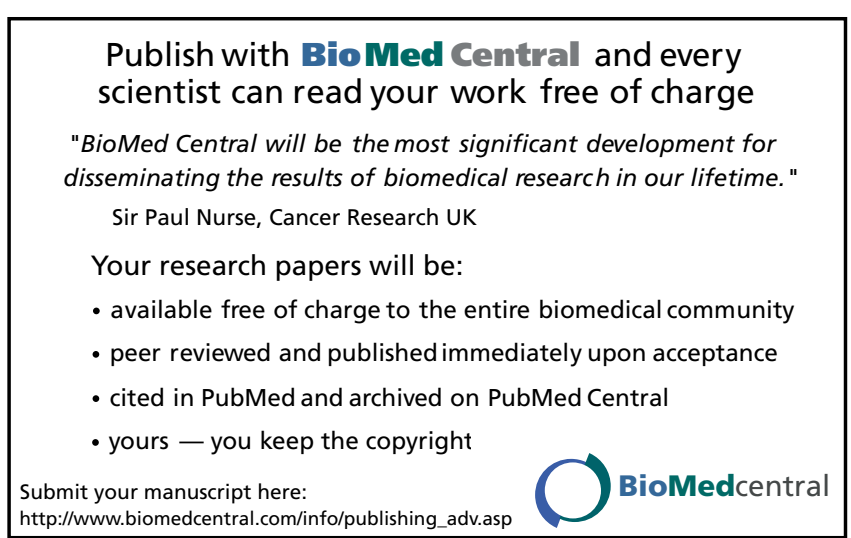

